Article

\title{
Open-Switch Fault Diagnosis Algorithm and Tolerant Control Method of the Three-Phase Three-Level NPC Active Rectifier
}

\author{
Jun-Hyung Jung ${ }^{1}{ }^{\oplus}$, Hyun-Keun $\mathrm{Ku}^{2}$, Yung-Deug Son ${ }^{3} \mathbb{C}$ and Jang-Mok Kim ${ }^{1, *}$ \\ 1 Department of Electrical and Computer Engineering, Pusan National University, Busan 46241, Korea \\ 2 Converter Station Construction Team, Korea Electric Power Corporation, Naju, Jeollanam-do 58322, Korea \\ 3 Department of Mechanical Facility Control Engineering, Korea University of Technology and Education, \\ Cheonan, Chungnam 31253, Korea \\ * Correspondence: jmok@pusan.ac.kr; Tel.: +82-51-510-2366
}

Received: 2 June 2019; Accepted: 26 June 2019; Published: 28 June 2019

\begin{abstract}
This paper proposes a fault diagnosis and tolerant control methods for an open-switch fault caused in a three-phase three-level neutral-point-clamped (NPC) pulse-width modulation (PWM) active rectifier. The open-switch fault in the three-level NPC active rectifier causes a distortion in the input phase current and a ripple in the DC-link capacitor voltage. Therefore, proper fault diagnosis and tolerant control methods are required to prevent additional failures and performance degradation in the rectifier system. This paper conducted a detailed analysis of the effect of the single open-switch fault on the NPC PWM active rectifier and proposed a fault diagnosis method utilizing the DC link voltage and the phase angle of the input grid voltage. Furthermore, this paper proposes a fault-tolerant control method to reduce the effect of the open-switch fault by compensating a distorted reference voltage. The effectiveness of the proposed fault diagnosis and tolerant control methods are verified through experimental results.
\end{abstract}

Keywords: three-level neutral-point clamped (NPC) active rectifier; open-switch fault; fault diagnosis and tolerant control method; space vector modulation (SVM)

\section{Introduction}

Multilevel converter topologies provide advantages in terms of increasing the allowable DC-link voltage and the better harmonics of the input current in comparison with the conventional two-level converters. Hence, three-level neutral-point clamped (NPC) topology systems have been researched in several papers and widely used in various industries. The research topics on the NPC topology systems can be categorized into several groups. Most of the research is related to pulse-width modulation (PWM) techniques for improved performance [1-3] and balancing algorithms of the neutral-point voltages [4-8]. As the results of various research efforts, the performance of NPC topology systems has been greatly improved.

Since the three-level NPC topology has been widely applied to various industries, the system reliability has emerged as an important issue [9]. The converter system consists of a number of components such as a harmonic filter, current and voltage transducers, gate driver circuits and power semiconductors, such as insulated gate bipolar transistors (IGBTs). For this reason, this system is vulnerable to various failures. The faults related to the switching devices, gate drive circuits and IGBTs are among the major issues that need to be dealt with in three-level NPC converter topology. Those faults in the switching devices are further classified into short-circuit faults and open-switch faults. Generally, short-circuit faults are caused by a malfunction of the gate drive circuit and an intrinsic failure of the IGBT, such as over-voltage and avalanche stress [10]. If the short-circuit fault occurs in 
the converter system, the circuit breakers or fuses immediately disconnect the power grid from the converter system to avoid the destruction of the system [11,12]. On the other hand, open-switch faults do not cause the converter system shutdown but degrade the performance of the system.

An open-switch fault in three-phase three-level NPC converter system leads to the distortion of the input phase current due to the change of the current path. The distorted current causes a fluctuation in the DC-link capacitor voltage and a voltage imbalance between the upper and lower capacitors. If the converter system is continuously operated under the open-switch fault condition, additional failures might occur on other devices and systems connected with the DC-link. In general, the converter system will pause to prevent further failure and repair. However, a sudden shutdown of the converter system causes significant financial losses in a renewable power generation or at some production plants. For this reason, a fault diagnosis and tolerant control method are required to continue operating the converter system.

In order to improve the reliability and safety of the system under the open-switch fault condition, various fault diagnosis and tolerant control methods have been proposed in several papers. In the case of the fault diagnosis for the open-switch fault, most studies are based on a phase current measured by sensors to identify the faulty switch. The open-switch fault in the two-level PWM AC/DC converter system can be detected using the derivative of the current vector's angle [13,14]. In [15,16], the pattern of current vector or an absolute normalized value of current on the $\mathrm{d}-\mathrm{q}$ frame is utilized to identify the faulty switch. The diagnosis methods based on the radius, residual and shape of the current pattern are proposed for the three-level NPC converter in [17-21]. In the case of the three-level T-type rectifier, the current shape according to the phase angle, is used to identify the fault [22]. Instead of using the phase current, the open-switch fault can be detected by pole voltage and clamped diode current measured by additional sensor circuits [23,24]. However, these methods are not recommended due to the additional cost of the sensor circuits. Previous research works $[25,26]$ have shown that a vector trajectory of the DC-link voltage ripple can be used to detect single or multiple open-switch faults of inner switches in three-level NPC active rectifiers.

In recent years, various fault-tolerant control methods for AC/DC converter systems have been researched. In three-phase two-level PWM converters, the fault-tolerant control method is proposed through the modification of the PWM switching patterns [13]. This method can improve the efficiency and power factor as well as the distortion and imbalance of the grid current under the fault condition. In [25], the tolerant control method similar to the method of [13] for the open-switch fault of inner switches in three-level NPC active rectifiers is proposed. However, although the space vector diagram of the three-level converter is subdivided into 36 regions as compared to the two-level converter which has only 6 regions, the effect of the fault on the distortion of the voltage reference and its tolerant control method are not analyzed or described in detail according to each sector and region. In the case of an inner open-switch fault in the three-level T-type converter, a distorted current can be restored by replacing the redundant vector and converting the switching mode to two-level switching [22]. In [27], fault-tolerant control injecting a reactive current is proposed for open-switch faults of outer switches in three-level NPC and T-type rectifiers. Although the current distortion is restored, the injected reactive current drops the power factor. To overcome this disadvantage, [28] proposes a fault-tolerant control method adding a compensation value to the reference voltages for the outer switches of three-level rectifiers.

In this paper, a fault diagnosis algorithm and tolerant control method for single open-switch faults of three-level NPC active rectifier systems is proposed. The concept of detecting the faulty switch using DC voltage ripples has been introduced in previous works $[25,26]$. However, specific implementation and verification of the proposed fault diagnosis have not been described. Following on from this research, this paper analyzes the effects of open-switch faults on the input phase currents and DC-link capacitor voltages, and proposes a specific fault diagnosis algorithm based on the ripple of DC-link capacitor voltage and the phase angle obtained from a phase-locked loop (PLL). In addition, this paper classifies the open-switch fault into three cases that can occur in three-level NPC active rectifiers, and 
analyzes the distortion of the voltage vector due to the fault in each case. From the results of this analysis, the fault-tolerant control method to restore the distorted reference voltage for each fault case is proposed in this paper. The imbalance and distortion of the input phase current can be improved by compensating the distorted reference voltage to be close to its original reference. As a result, the power factor can be improved and the ripple of the output DC-link voltage can be reduced. Furthermore, additional failures of the system connected to the DC-link can be prevented. The effectiveness of the proposed fault diagnosis and tolerant control methods are verified through experimental results.

\section{Open-Switch Fault in Three-Level NPC Active Rectifier}

As shown in Figure 1, the three-phase three-level NPC converter is composed of twelve active switching devices $\left(S_{x 1} \sim S_{x 4},(x=\mathrm{a}, \mathrm{b}, \mathrm{c})\right)$ with the anti-parallel diodes $\left(D_{x 1} \sim D_{x 4}\right)$, six clamped diodes $\left(D_{x z 1} \sim D_{x z 2}\right)$ and two DC-link capacitors $\left(C_{d c_{-} H}, C_{d c_{-} L}\right)$. The uppermost and lowermost switches in each leg, $S_{x 1}$ and $S_{x 4}$, are called the 'outer switches' while the two middle switches, $S_{x 2}$ and $S_{x 3}$ are referred to as 'inner switches'.

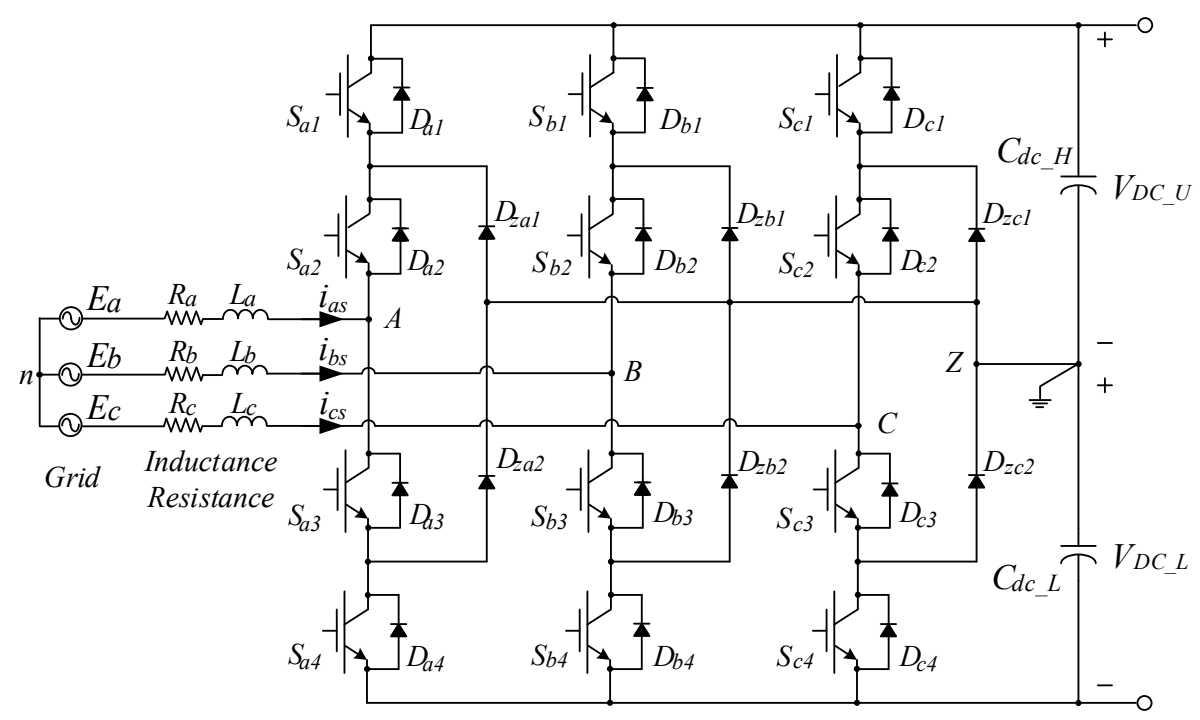

Figure 1. Circuit configuration of the three-phase three-level NPC PWM converter.

The operation of each leg can be expressed by three switching states, $\left({ }^{\prime} \mathrm{P}^{\prime},{ }^{\prime} \mathrm{O}\right.$ ' and ' $\mathrm{N}$ '), and their corresponding leg voltages at terminal ' $x$ ' with respect to the neutral point ' $z$ ' are shown in Table 1 . The switching state ' $\mathrm{P}$ ' denotes that two upper switches $S_{x_{1}}$ and $S_{x_{2}}$ are ' $\mathrm{ON}^{\prime}$ ' and the leg voltage $V_{x z}$ is $+V_{D C} / 2$. The switching state ' $\mathrm{O}$ ' means that two inner switches $S_{x 2}$ and $S_{x 3}$ are ' $\mathrm{ON}$ ' and $V_{x z}$ is $0 \mathrm{~V}$. During the switching state ' $\mathrm{N}$ ', the two lower switches $S_{x 3}$ and $S_{x 4}$ are turned on and $V_{x z}$ is $-V_{D C} / 2$ [29].

Table 1. Relationship between phase voltage and switching signals.

\begin{tabular}{cccccc}
\hline & & \multicolumn{4}{c}{$\begin{array}{c}\text { Switching Signals } \\
(x=\mathbf{a}, \mathbf{b}, \mathbf{c})\end{array}$} \\
\cline { 3 - 6 } Phase Voltage $\mathbf{V}_{x z}$ & Switching States & \multicolumn{4}{c}{$S_{x 4}$} \\
\cline { 3 - 6 } & & $S_{x 1}$ & $S_{x 2}$ & $S_{x 3}$ & $S_{x 4}$ \\
\hline$V_{D C} / 2$ & $\mathrm{P}$ & On & On & Off & Off \\
0 & $\mathrm{O}$ & Off & On & On & Off \\
$-V_{D C} / 2$ & $\mathrm{~N}$ & Off & Off & On & On \\
\hline
\end{tabular}

Figure 2 shows the current paths of the three-phase NPC converter based on the switching states and the phase current direction. According to the direction of the phase current $i_{x}$, there are six possible current paths in the respective leg of the three-level NPC converter. Figure 2a shows the positive current flowing through $D_{x 2}$ and $D_{x 1}$ towards the DC-link positive point during the switching state ' $\mathrm{P}^{\prime}$. At the switching state ' $\mathrm{O}$ ', as shown in Figure $2 \mathrm{~b}$, the positive current flows through $S_{x 3}$ and $D_{z x 2}$ to 
the neutral point. In most cases, the positive current flows through the path of switching states ' $\mathrm{P}$ ' and ' $\mathrm{O}$ ' if the NPC converter is well controlled with the unity power factor. In Figure 2c, the positive current flows through $S_{x_{3}}$ and $S_{x 4}$ during the ' $\mathrm{N}$ ' state. Similarly, there are three negative current paths according to the switching states, as shown in Figure $2 \mathrm{~d}-\mathrm{f}$. At the switching state ' $\mathrm{P}$ ', the current flows through $S_{x 1}, S_{x 2}$ from the positive point of the DC-link. The ' $\mathrm{O}$ ' state leads the current to flow through $D_{z x 1}, S_{x 2}$ from the neutral point of the DC-link to phase terminal. Additionally, both $D_{x 3}$ and $D_{x 4}$ provide current path during the switching state ' $\mathrm{N}$ '.

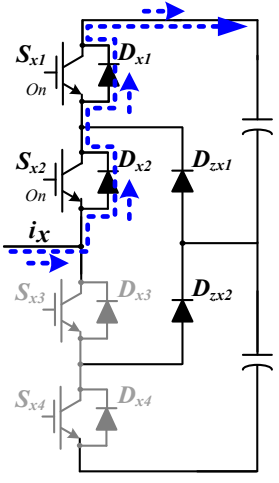

(a)

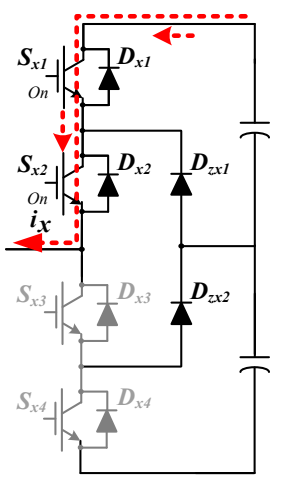

(d)

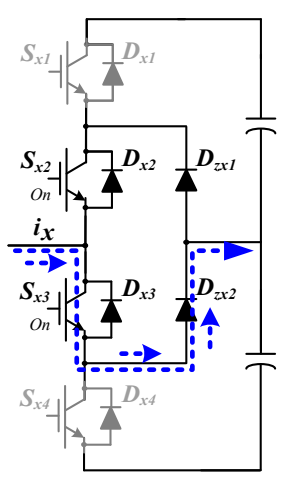

(b)

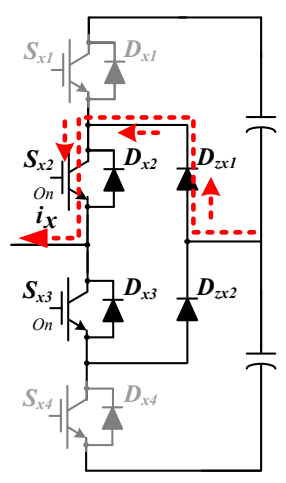

(e)

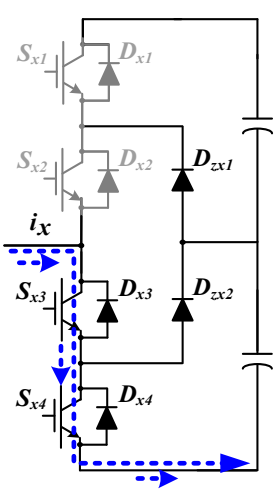

(c)

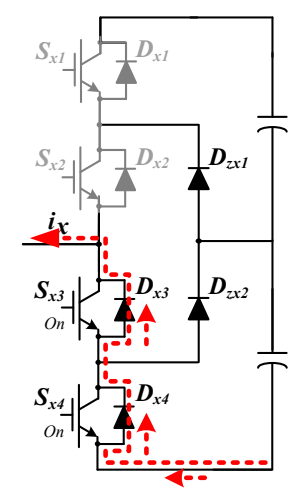

(f)

Figure 2. Current paths according to switching states and the current direction: (a) P-state, $i_{x s}>0$; (b) O-state, $i_{x s}>0$; (c) N-state, $i_{x s}>0$; (d) P-state, $i_{x s}<0$; (e) O-state, $i_{x s}<0$; (f) N-state, $i_{x s}<0$.

When the three-level NPC converter is operated as an active rectifier system, the cases of Figure 2c,d rarely occur if the active rectifier system is controlled to have a unity power factor. Therefore, this paper considers a single open-switch fault of the inner switches, $S_{x_{2}}$ or $S_{x 3}$, because the open-switch fault of the outer switches, $S_{x 1}$ and $S_{x 4}$, have little effect on the operation of the rectifier system [18].

\section{1. $S_{x 2}$ Open-Switch Fault}

When an open-switch fault occurs in the leg of the converter, the current cannot flow through the faulty switch. Considering this characteristic, an open-switch fault of $S_{x_{2}}$ affects the switching states ' $\mathrm{P}$ ' and ' $\mathrm{O}$ ' under a negative current flow shown in Figure 2d,e. However, due to the unity power factor operation of the converter, the switching state ' $\mathrm{P}$ ' is not considered.

Under healthy conditions, the negative current flows through $D_{z x 1}$ and $S_{x 2}$ from the neutral point of the DC-link during the switching state ' $\mathrm{O}$ ' as presented in Figure 2e. But, if an open-switch fault of $S_{x 2}$ occurs, the current path is changed into a path through $D_{x 3}$ and $D_{x 4}$, as shown in Figure $2 \mathrm{f}$. This result means that the switching state of the phase is changed from ' $\mathrm{O}$ ' to ' $\mathrm{N}$ ' and the reference voltage of the converter is distorted. The distorted reference voltage causes the distortion of the three-phase input currents and the ripple of the DC-link capacitor voltage, as shown in Figure 3a,b. 


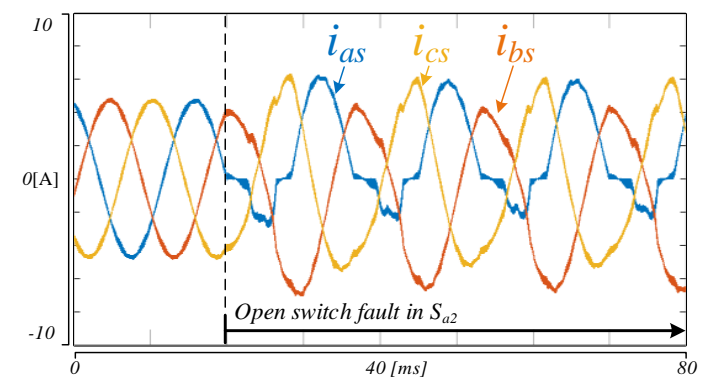

(a)

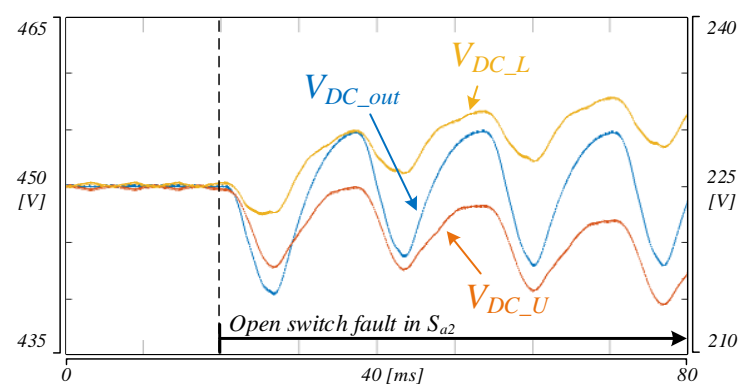

(b)

Figure 3. Three-phase currents and DC-link capacitor voltages under $S_{x 2}$ open-switch fault condition: (a) three-phase input current $\left(S_{a 2}\right)$; (b) DC-link capacitor voltage $\left(S_{a 2}\right)$.

\section{2. $S_{x 3}$ Open-Switch Fault}

In case of an open-switch fault of $S_{x_{3}}$, the fault of $S_{x 3}$ affects the ' $\mathrm{O}$ ' and ' $\mathrm{N}$ ' switching states during the positive current flow, as shown in Figure $4 \mathrm{a}, \mathrm{b}$. If the converter is well controlled to have a unity power factor, only the switching state ' $\mathrm{O}$ ' is affected by the fault of $S_{x 3}$ during the positive current.

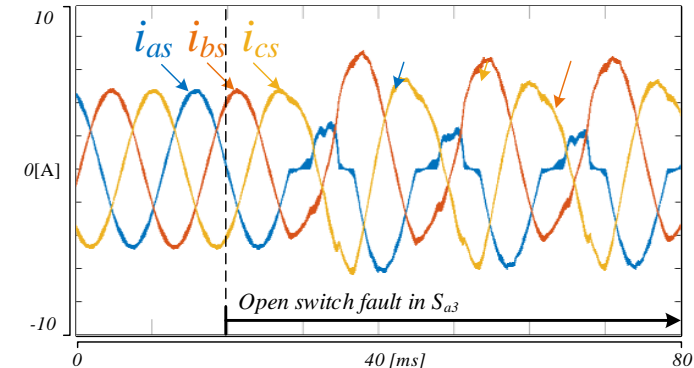

(a)

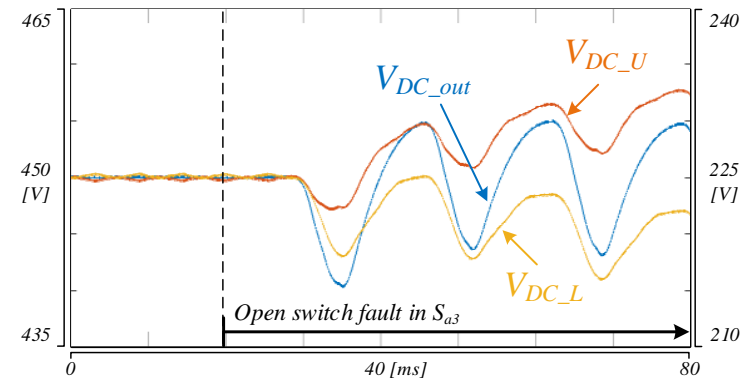

(b)

Figure 4. Three-phase currents and DC-link capacitor voltages under $S_{x 3}$ open-switch fault condition: (a) three-phase input current $\left(S_{a 3}\right)$; (b) DC-link capacitor voltage $\left(S_{a 3}\right)$.

Under the open-switch fault condition of $S_{x_{3}}$, the converter cannot have the current path given in Figure $2 \mathrm{~b}$ because $S_{x 3}$ does not allow the current to flow. For this reason, the positive current changes its flow to the path shown in Figure 2a, which results in the switching state being changed from ' $\mathrm{O}$ ' to ' $\mathrm{P}$ '. In conclusion, the open-switch fault of $S_{x_{3}}$ causes the current distortion in the positive half cycle and DC-link capacitor voltage fluctuation, as shown in Figure $4 \mathrm{~b}$.

This paper specifically focuses on the open-switch fault of $S_{a 2}$, as a case study. The effects of the $S_{x 2}$ and $S_{x 3}$ open-switch fault are symmetrical with respect to the current direction. Also, the effects of the fault of $S_{a n}, S_{b n}$ and $S_{c n}$ are shown by a $120^{\circ}$ phase difference. Therefore, the proposed fault diagnosis and tolerant control method for the open-switch fault of $S_{a 2}$ can also be applied to the other fault cases in a similar way.

\section{Open-Switch Fault Diagnosis Algorithm Using Vector Trajectory of the DC-Link Voltage}

The three-phase NPC active rectifier can provide a controllable output DC-link voltage and a bidirectional power flow with a unity power factor. Even though the open-switch fault of the NPC converter does not cause the system shutdown, it deteriorates the performance of, and leads to the fatigue accumulation, in the system. Therefore, a proper diagnosis method for the open-switch fault should be applied for the system to prevent other device faults. The proposed open-switch fault diagnosis algorithm is based on the DC-link voltage and the vector trajectory of the DC-link voltage ripple. The vector trajectory can be acquired by a combination of the DC-link voltage oscillatory components and the phase angle of the grid source. The phase angle can be acquired through the PLL 
from the phase voltage of the grid. The vector trajectory represents the magnitude and phase angle of the DC-link voltage ripple.

Figure 5a shows the ripple component of the DC-link capacitor voltage and the phase angle of the grid voltage under healthy conditions. Under this condition, the DC-link voltage is stably controlled and the vector trajectory is located in a polar coordinate center. Under the fault condition of $S_{x 2}$, on the other hand, the DC-link voltage has a ripple, as shown in Figure 5b, because the three-phase input currents are distorted by the open-switch fault. In this case, the vector trajectory of the DC-link voltage has a circle shape and this is located in a range of the phase angle between $2 \pi / 3$ and $\pi$.

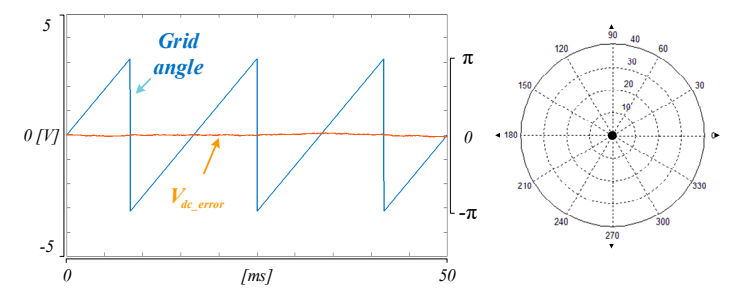

(a)

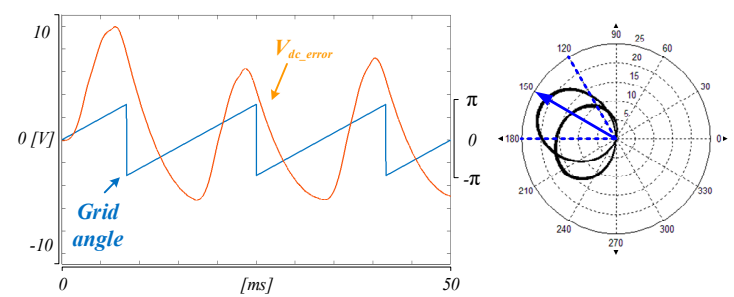

(b)

Figure 5. DC-link capacitor voltage and vector trajectory according to open-switch fault of $S_{a 3}$. (a) Healthy condition; (b) Faulty condition.

Figure 6 describes the vector trajectories and the representative vector of the DC-link voltage ripple according to the open-switch fault of the six inner switches. The vector trajectories for the different inner open-switch faults have a phase angle difference of $60^{\circ}$. If an open-switch fault of inner switch occurs, the vector of the DC voltage (blue solid line) is located within one of the six regions, and the position of the faulty switch can be determined. Table 2 represents the detection range of the phase angle and its index number according to the cases of the open-switch fault. For example, if the fault occurs in $S_{a 2}$, the vector trajectories of the DC-link voltage ripple is placed in a range of the phaseangle between $2 \pi / 3$ and $\pi$. The index number is determined as ' 3 ' through the diagnosis algorithm described in Figure 7.

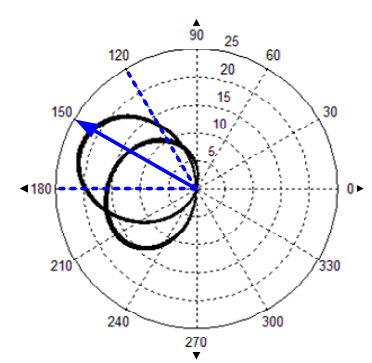

(a)

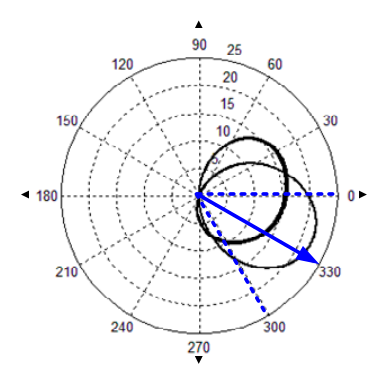

(d)

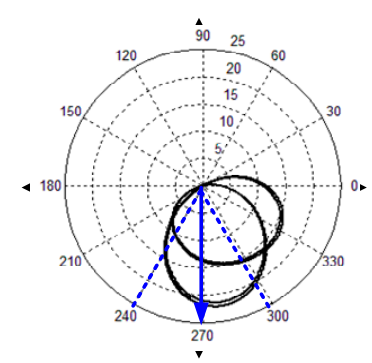

(b)

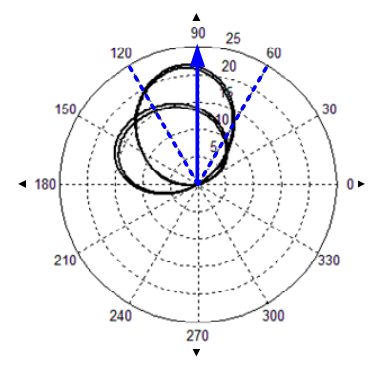

(e)

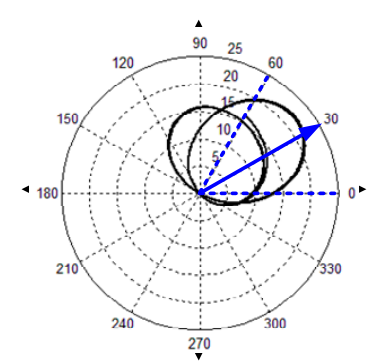

(c)

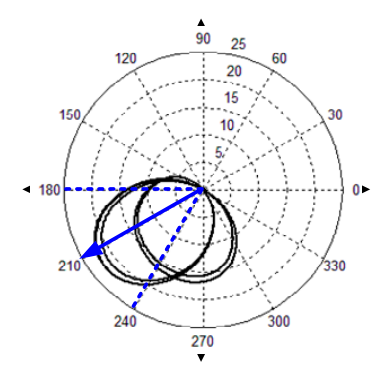

(f)

Figure 6. Vector trajectory and representative vector of DC-link voltage under open-switch fault condition. (a) $S_{a 2}$ fault; (b) $S_{b 2}$ fault; (c) $S_{c 2}$ fault; (d) $S_{a 3}$ fault; (e) $S_{b 3}$ fault; (f) $S_{c 3}$ fault. 
Table 2. Detection region and index on open-switch fault.

\begin{tabular}{ccc}
\hline Open-Switch Fault & Detection Region $\left(\boldsymbol{\theta}_{\text {grid }}\right)$ & Index $(\boldsymbol{R})$ \\
\hline$S_{a 2}$ & $2 \pi / 3 \sim \pi$ & 3 \\
$S_{a 3}$ & $5 \pi / 3 \sim 2 \pi$ & 6 \\
$S_{b 2}$ & $4 \pi / 3 \sim 5 \pi / 3$ & 5 \\
$S_{b 3}$ & $\pi / 3 \sim 2 \pi / 3$ & 2 \\
$S_{c 2}$ & $0 \sim \pi / 3$ & 1 \\
$S_{c 3}$ & $\pi \sim 4 \pi / 3$ & 4 \\
\hline
\end{tabular}

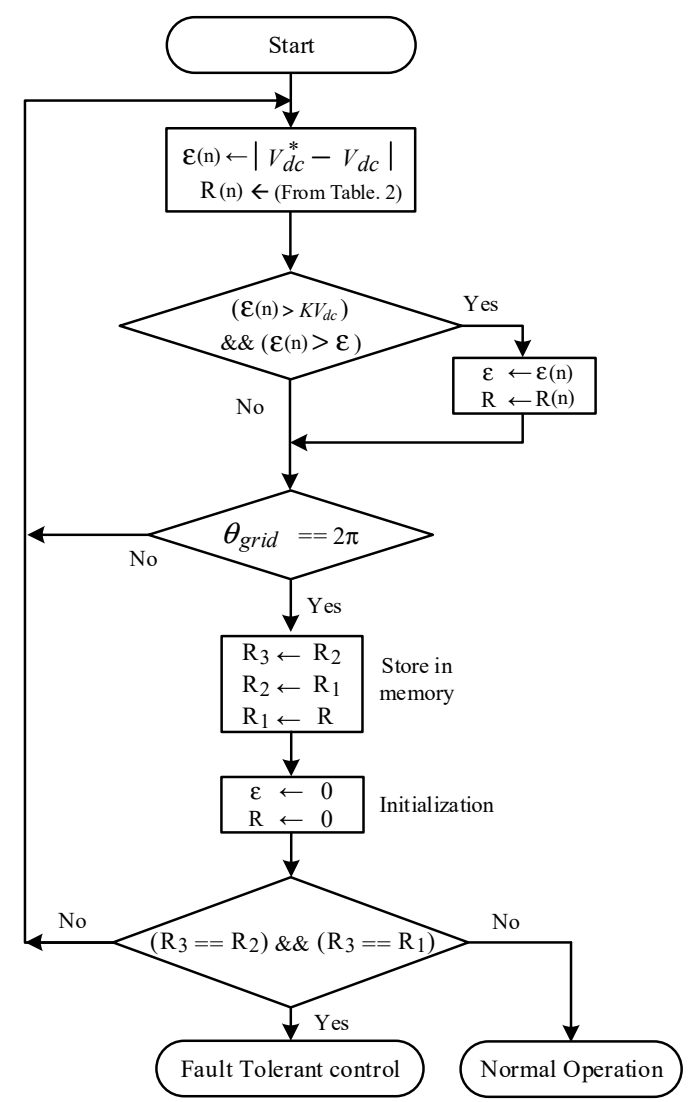

Figure 7. Flowchart of the proposed open-switch fault diagnosis algorithm.

Figure 7 shows the flowchart of the proposed open-switch fault diagnosis algorithm. $\varepsilon(n)$ is the absolute value of the difference between the DC-link voltage reference and the sampled DC-link voltage. $R(n)$ means the index number of Table 2 and it is determined according to the phase angle of the input voltage at each sampling period and the definition in Table 2. $\theta_{\text {grid }}$ is the phase angle of the input voltage acquired from PLL. $\varepsilon(n)$ is $R(n)$ can be obtained at the beginning of each sample period (100 us). If $\varepsilon(n)$ is more than $K V_{D C}$ and the largest value of previously sampled $\varepsilon, \varepsilon$ is updated to $\varepsilon(n)$ as the maximum of the sampled values so far and $R$ is also updated to $R(n)$. This process is repeated every sampling period until the phase angle $\theta_{\text {grid }}$ becomes $2 \pi$. If the open-switch fault occurs at $S_{a 2}$, for example, the DC voltage at the phase angle between $2 \pi / 3$ and $\pi$ occurs a maximum and the index $R$ is set to 3 . When $\theta_{\text {grid }}$ equals $2 \pi$, the previously stored $R_{1}$ and $R_{2}$ are stored in $R_{2}$ and $R_{3}$, respectively, and the acquired $R$ in this period is stored in $R_{1}$. After this process, $\varepsilon$ and $R$ are initialized to zero. Finally, if $R_{1}, R_{2}$ and $R_{3}$ are equal to each other, the faulty switch can be detected and located. This indicates that the same $R$ value occurs continuously for three periods of $\theta_{\text {grid }}$. If the number of the process is too high or too low, the fault diagnosis may not work well or fail to operate. If $R_{1}, R_{2}$ and $R_{3}$ are not equal to each other, continue the normal operation. 


\section{Proposed Fault-Tolerant Control Method}

The proposed fault-tolerant control method for the single open-switch fault of the three-level NPC active rectifier is based on the methodology introduced in [13]. In [24], the effect of the fault is analyzed for only two sectors. In the case of the three-level topologies, however, the sector is divided into six regions, and therefore, an analysis is required for each region. Thus, this paper analyzes the effect of the fault on each region and classifies the open-switch fault into three cases. As a result of the analysis, the fault-tolerant control method for three fault cases is proposed.

The reference voltage of the three-phase three-level NPC converter can be implemented by using the SVPWM. The reference $V^{*}$ can be made by a combination of the three nearest voltage vectors as expressed in (1).

$$
\vec{V}^{*}=\alpha \vec{V}_{\text {Active } 1}+\beta \vec{V}_{\text {Active } 2}+\gamma \vec{V}_{\text {Base. } n}+\gamma \vec{V}_{\text {Base. } p}\left(\alpha=\frac{T_{1}}{T_{s}}, \beta=\frac{T_{2}}{T_{s}}, \gamma=\frac{T_{0} / 2}{T_{s}}\right)
$$

$T_{S}$ is a sampling period of the current controller of the PWM converter. $T_{0}$ is the time of the small voltage vectors $V_{\text {Base.n }}$ and $V_{\text {Base.p. }}$. In the three-level system, the PWM pattern begins with the nearest small voltage vector. So, this small vector is called a base voltage vector in this paper. The small voltage vector is implemented as a redundant vector because the P-type and $\mathrm{N}$-type small vectors have the same duration. Other two voltage vectors are referred to as an active voltage vector. $T_{1}$ is the time for the active voltage vector $V_{\text {Active } 1}$. $T_{2}$ is the time for the active voltage vector $V_{\text {Active2 }}$.

In this paper, the effect of a $S_{a 2}$ open-switch fault on the reference voltage and its fault-tolerant method are classified into three cases according to the number of the distorted switching voltage vectors. Also, this paper is focused on the fault caused in sector B and C, as shown in Figure 9. Sector $\mathrm{D}$ and $\mathrm{E}$ are symmetrical with the sector $\mathrm{B}$ and $\mathrm{C}$, respectively. The result of the fault and the tolerant control will be obtained by using the same method.

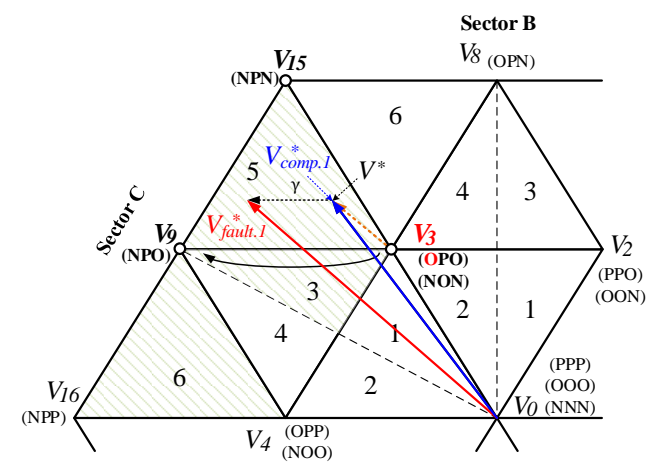

(a)

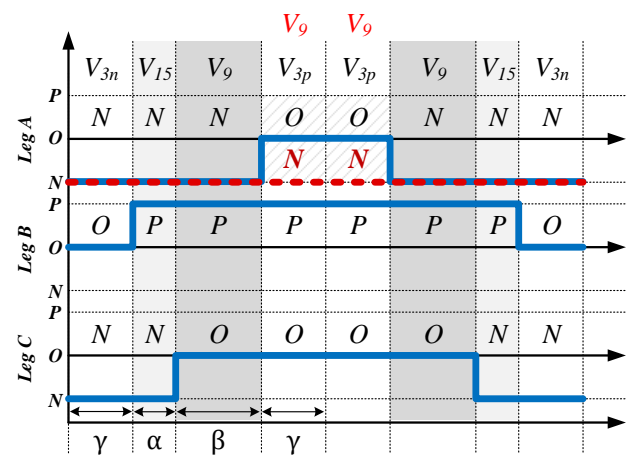

(b)

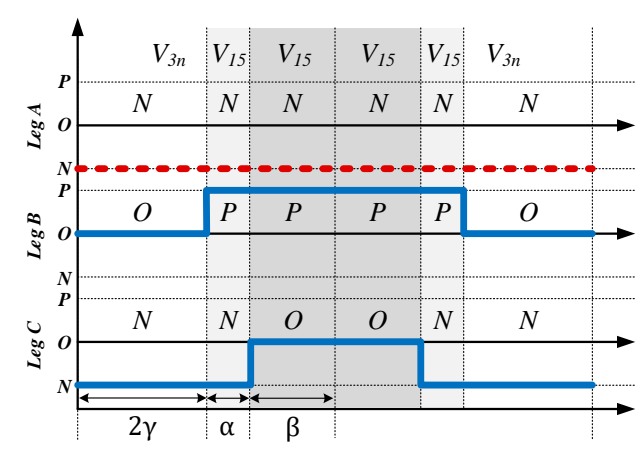

(c)

Figure 8. Reference voltage and switching patterns under the fault case 1. (a) Distortion and compensation of the reference voltage; (b) Switching pattern under the fault condition; (c) Switching pattern with the proposed fault-tolerant control method. 
Figure 8 a shows the distortion of the reference voltage under the fault case 1 which has a single distortion of the voltage vector. This fault case is caused when the reference voltage is placed in region 3,5 and 6 of sector $C$. Before the fault occurs, the reference voltage is generated by the nearest three vectors $V_{3}, V_{9}$ and $V_{15}$, as shown in Figure 8a, and the equation of the voltage vector can be written as (2).

$$
\vec{V}^{*}=\alpha \vec{V}_{15}+\beta \vec{V}_{9}+\gamma \vec{V}_{3 n}+\gamma \vec{V}_{3 p}
$$

If $S_{a 2}$ open-switch fault occurs, the switching state of the phase 'A' generates only N-state. For this reason, the P-type small vector $V_{3 p}([\mathrm{OPO}])$ cannot be generated. The voltage vector $V_{3 p}$ is converted into the medium vector $V_{9}$ ([NPO]) due to $S_{a 2}$ open switch fault, as shown in Figure $8 \mathrm{~b}$. So, the reference voltage is distorted from $V^{*}$ to $V^{*}$ fault 1 and the faulted reference voltage $V_{\text {fault }}^{*}$ can be expressed as (3).

$$
\begin{aligned}
\vec{V}_{\text {fault.1 }}^{*} & =\alpha \vec{V}_{15}+\beta \vec{V}_{9}+\gamma \vec{V}_{3 n}+\gamma \vec{V}_{9} \\
& =\alpha \vec{V}_{15}+(\beta+\gamma) \vec{V}_{9}+\gamma \vec{V}_{3 n}
\end{aligned}
$$

Under the fault condition of case 1, the distorted voltage vector is the P-type small vector, which is the base vector. Since the small vector is the redundant vector, the distorted reference voltage can be restored by increasing the switching time for the vector $V_{3 n}$ as well as the time for the $V_{3 p}$ as described in Figure 8c. The compensated reference voltage $V^{*}$ comp 1 is given in (4). Therefore, the distorted reference voltage under the fault case 1 can be perfectly restored to the original reference voltage by using the proposed tolerant method.

$$
\vec{V}_{\text {comp } .1}^{*}=\alpha \vec{V}_{15}+\beta \vec{V}_{9}+2 \gamma \vec{V}_{3 n}
$$

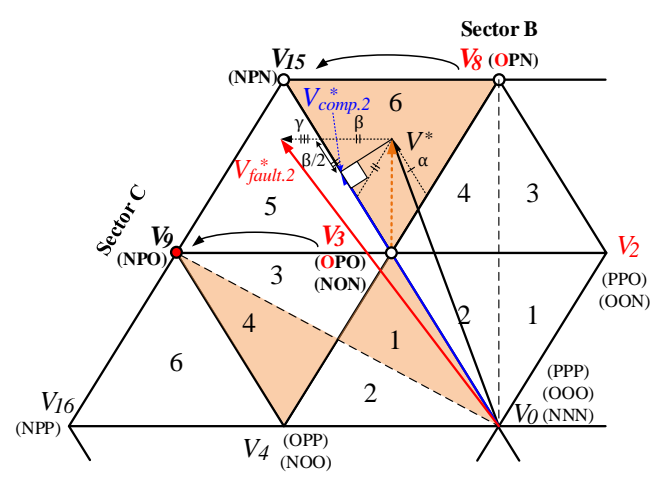

(a)

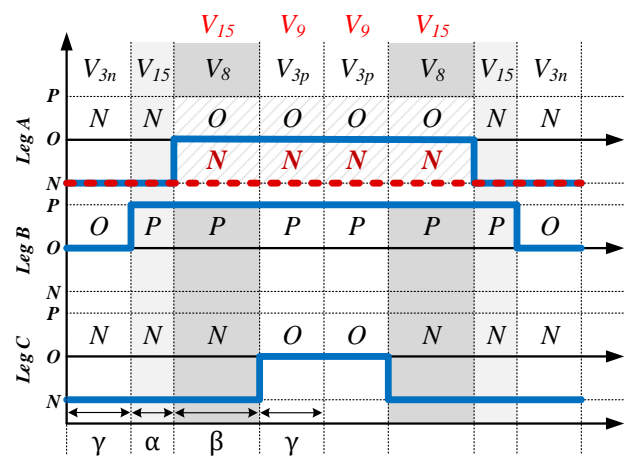

(b)

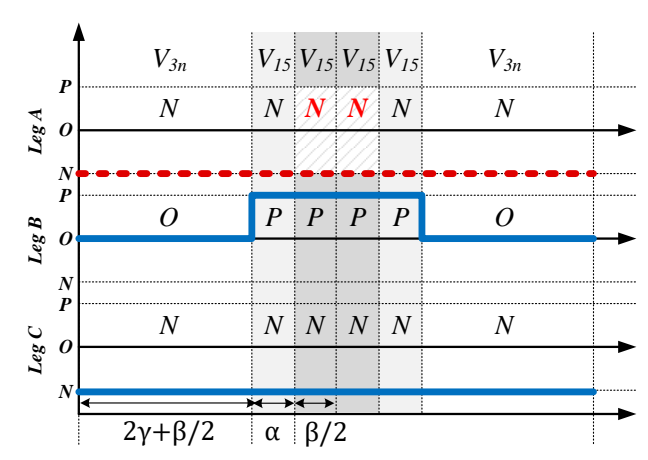

(c)

Figure 9. Reference voltage and switching patterns under the fault case 2. (a) Distortion and compensation of the reference voltage; (b) Switching pattern under the fault condition; (c) Switching pattern with the proposed fault-tolerant control method. 
Fault case 2 is shown in Figure 9a. Two voltage vectors are converted when the reference voltage is located in region 6 of sector $B$ and region 1 and 4 of sector $C$ under the fault condition. As described in Figure $9 \mathrm{~b}$, voltage vectors $V_{3 p}$ ([OPO]) and $V_{8}([\mathrm{OPN}])$ are converted into $V_{9}$ ([NPO]) and $V_{15}$ ([NPN]), respectively. It means that the faulted reference voltage is placed in the region 5 of the sector $C$ because $V_{\text {fault } 2}^{*}$ is synthesized by the nearest vectors including the distorted vectors $V_{9}$ and $V_{15}$.

In case of fault case 2 , the distorted reference voltage cannot be compensated perfectly because the compensation of the reference voltage is limited inside a triangle made by the three vectors $V_{9}, V_{15}$ and $V_{3}$. However, the distorted reference voltage can be compensated partially by using a vector projection as described in Figure 9a. If the reference voltage is projected orthogonally onto the line connected between $V_{15}$ and $V_{3}$, it is the nearest available point based on the reference voltage. Under the fault

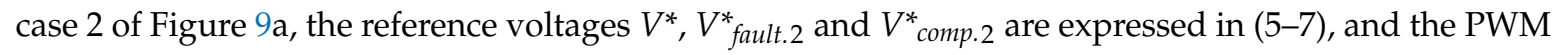
pattern can be changed from Figure $9 \mathrm{~b}$ using the proposed tolerant method, as shown in Figure 9c.

$$
\begin{gathered}
\vec{V}^{*}=\alpha \vec{V}_{15}+\beta \vec{V}_{8}+\gamma \vec{V}_{3 n}+\gamma \vec{V}_{3 p} \\
\vec{V}_{\text {fault.2 }}^{*}=(\alpha+\beta) \vec{V}_{15}+\gamma \vec{V}_{3 n}+\gamma \vec{V}_{9} \\
\vec{V}_{\text {comp. } 2}^{*}=(\alpha+\beta / 2) \vec{V}_{15}+(2 \gamma+\beta / 2) \vec{V}_{3 n}
\end{gathered}
$$

Figure 10 describes the reference voltage and switching patterns under fault case 3 . In fault case 3 , the reference voltage is seriously distorted, as depicted in Figure 10a, because the three voltage vectors are changed by the open switch fault of $S_{a 2}$. The faulted reference voltage is placed in region 5 of the sector $C$ because three voltage vectors $V_{2 n}([\mathrm{OON}]), V_{3 p}([\mathrm{OPO}])$ and $V_{8}([\mathrm{OPN}])$ are converted into $V_{3 n}([\mathrm{NON}]), V_{9}([\mathrm{NPO}])$ and $V_{15}([\mathrm{NPN}])$, respectively. It can be explained by the same approach used in fault case 2 . The original and the faulted reference voltage are expressed in (8) and (9), respectively.

$$
\begin{gathered}
\vec{V}^{*}=\alpha \vec{V}_{2}+\beta \vec{V}_{8}+\gamma \vec{V}_{3 n}+\gamma \vec{V}_{3 p} \\
\vec{V}_{\text {fault. } 3}^{*}=\beta \vec{V}_{15}+(\alpha+\gamma) \vec{V}_{3 n}+\gamma \vec{V}_{9}
\end{gathered}
$$

The distorted reference voltage can be compensated in a similar way as the fault case 2 . But the compensation of case 3 has a limitation because the projection of the reference voltage onto the line between $V_{15}$ and $V_{3}$ is restricted within the line. The compensated reference $V_{\text {comp. } 3}^{*}$ is concretely presented in (10) for the explanation of the limitation. To eliminate the effect of $V_{9}$ on the reference voltage, the switching time of $V_{3 n}$ is increased, as is the switching time of the distorted vector $V_{9}$. Additionally, the compensated time of $V_{15}$ will be determined by subtracting $(\alpha+\beta) / 2$ from $\beta$. The compensation time for the orthogonal projection of the original reference voltage can be represented as $(\alpha+\beta) / 2$. This compensation time should be lower than $\beta$. If $(\alpha+\beta) / 2$ is equal to or greater than $\beta$, then PWM pattern is made up of the only $V_{3 n}$.

$$
\begin{aligned}
\vec{V}_{\text {comp.3 }}^{*} & =\alpha \vec{V}_{3 n}+(\beta-(\alpha+\beta) / 2) \vec{V}_{15}+(\gamma+\gamma) \vec{V}_{3 n}+(\gamma-\gamma) \vec{V}_{9} \\
& =((3 \alpha+\beta) / 2+2 \gamma) \vec{V}_{3 n}+((\beta-\alpha) / 2) \vec{V}_{15}
\end{aligned}
$$

Table 3 shows the voltage reference voltage according to the regions of sector $B$ and $C$ under the normal, open-circuit fault of $S_{a 2}$ and tolerant control conditions. Figure 11 shows the region of the three fault-tolerant control cases under the $S_{a 2}$ open switch fault on the space vector diagram of the three-level NPC converter. Three tolerant control methods explained in Figures 8-10 of sector B and $C$ can be applied in sector $D$ and $E$, symmetrically. If the fault occurs in $S_{a 3}$, the regions of the tolerant control cases are symmetrical with the fault case of $S_{a 2}$ relative to the zero voltage vector $V_{0}$. Furthermore, the regions of the tolerant control for the fault caused in phase $\mathrm{A}, \mathrm{B}$ and $\mathrm{C}$ are 120 degrees symmetrical with respect to the zero voltage vector $V_{0}$. 


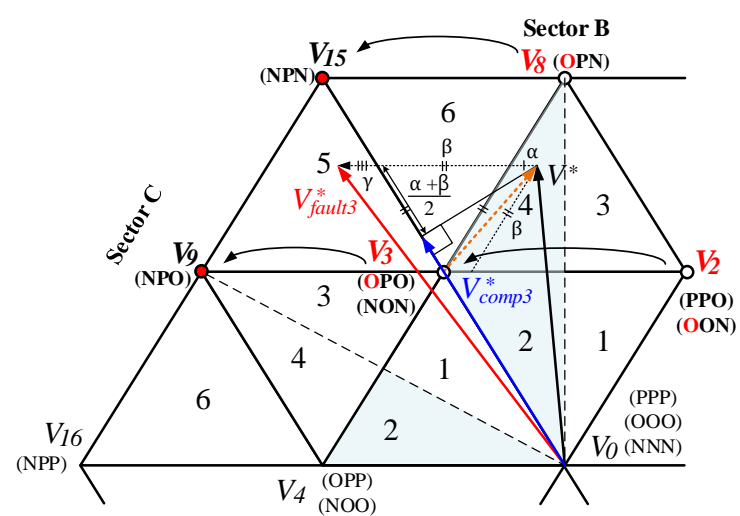

(a)

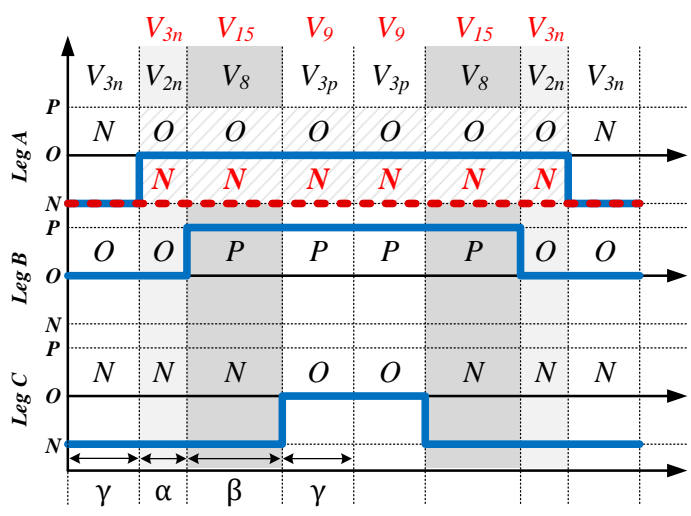

(b)

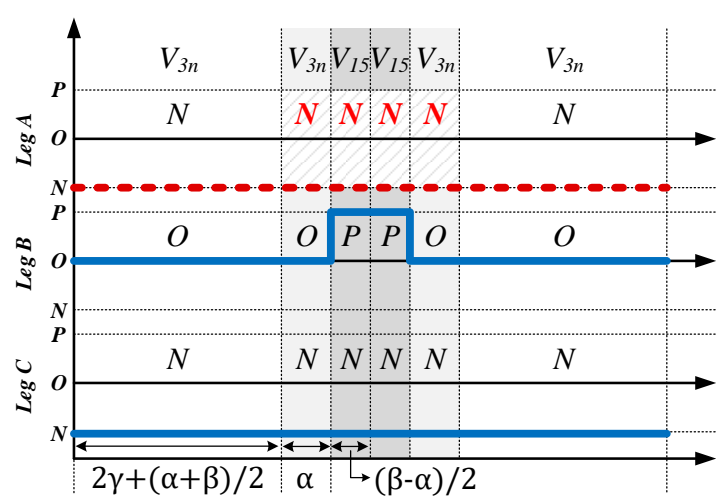

(c)

Figure 10. Reference voltage and switching patterns under the fault case 3. (a) Distortion and compensation of the reference voltage; (b) Switching pattern under the fault condition; (c) Switching pattern with the proposed fault-tolerant control method.

Table 3. Reference voltage according to the regions of sector B and C.

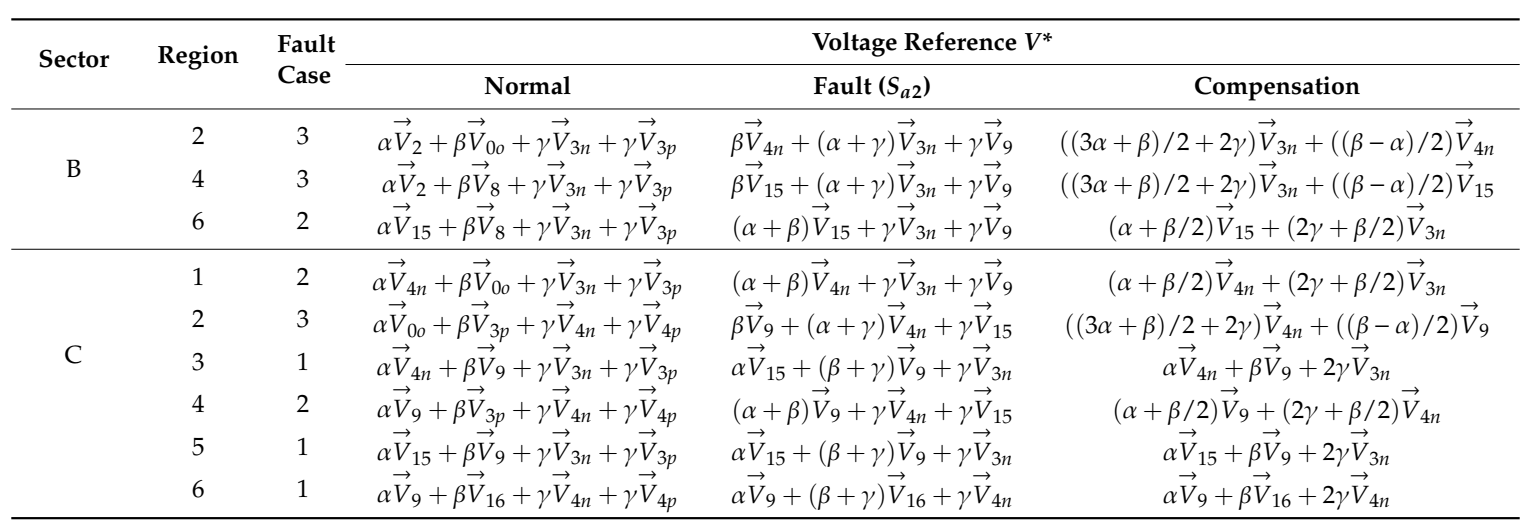




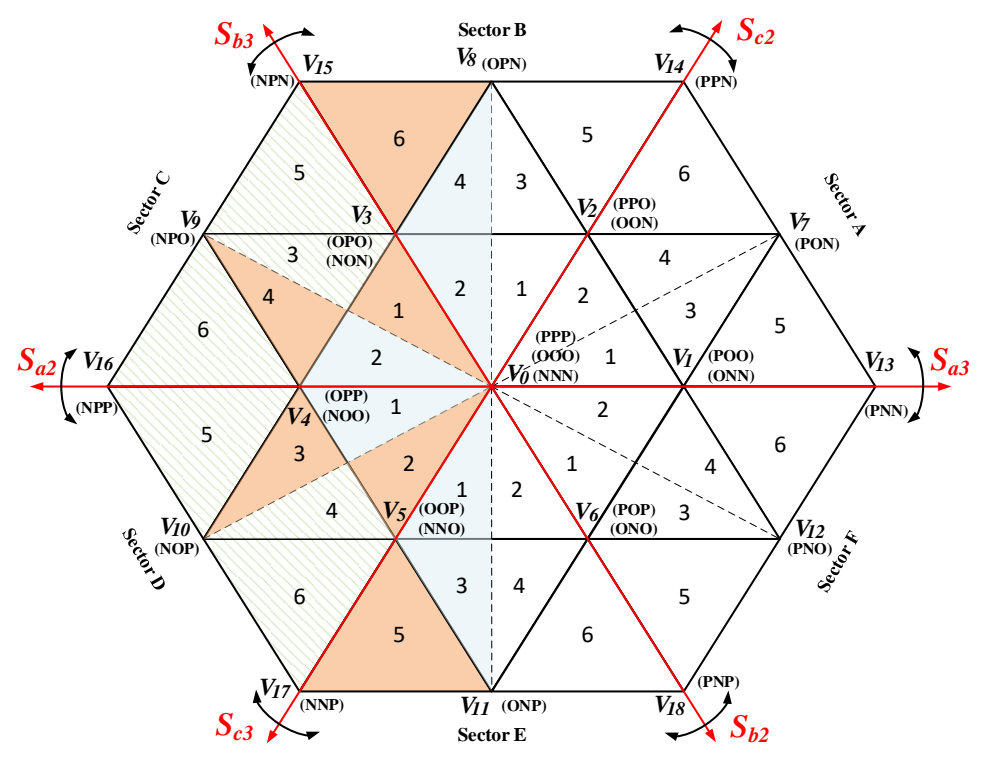

Figure 11. Regions of the proposed three tolerant control method cases on the space vector diagram.

\section{Experimental Results}

Various experiments are performed to verify the validity of the proposed open-switch fault diagnosis and tolerant control method, respectively. Table 4 shows the experimental specifications of the three-phase NPC converter. Figure 12 presents a hardware system used for the validation of the proposed method. This system consists of IGBT modules (SKM100GB128D), gate drivers (SKHI22B), voltage and current sensors and the control board based on the DSP (TMS320c28346). As mentioned in Section 4, this paper assumes that the open-switch fault occurs at $S_{a 2}$ and the experiment was carried out under $S_{a 2}$ fault condition for the simplification of the analysis and experiment.

Table 4. Specifications and conditions of the experiment.

\begin{tabular}{cccc}
\hline Input grid voltage & $3 \phi 220 \mathrm{~V}$ & Output DC-link voltage & $400 \mathrm{~V}$ \\
\hline Grid Frequency & $60 \mathrm{~Hz}$ & Output Power & $1 \mathrm{~kW}$ \\
\hline Input Filter & $5 \mathrm{mH}$ & PWM Method & SVPWM \\
\hline DC-link Capacitance & $1.35 \mathrm{mF}$ & Switching Frequency & $10 \mathrm{kHz}$ \\
\hline
\end{tabular}

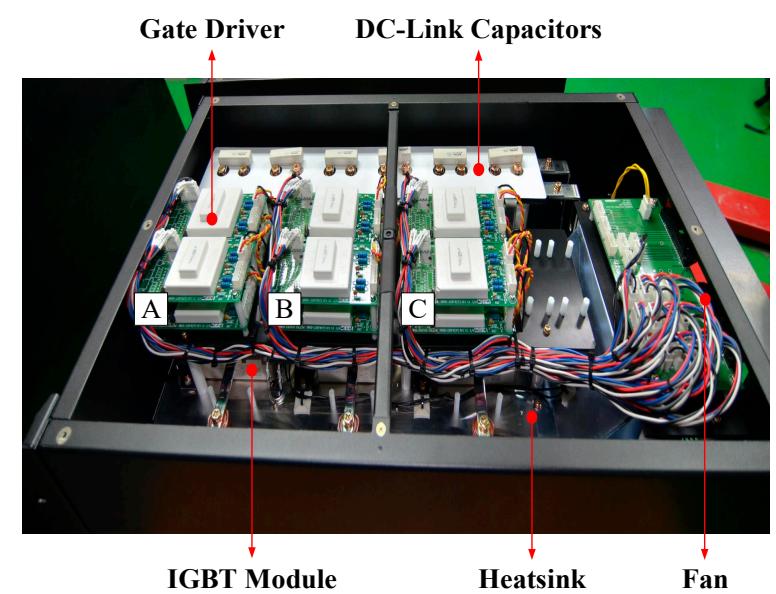

Figure 12. Experiment system of the three-level NPC active rectifier. 
Figure 13 shows the experimental result of the fault diagnosis algorithm for the open-switch fault of $S_{a 2}$, as explained in Figure 7. The index number $R$ is determined at every period of $16.6 \mathrm{~ms}$ $(60 \mathrm{~Hz})$ from the proposed fault diagnosis algorithm. Before the open-switch fault occurs, $R$ is changed irregularly. This means that the fault does not occur in the rectifier system. After the open-switch fault is caused in $S_{a 2}$, the phase current $i_{a}$ is distorted, and it can be confirmed that the fault-tolerant control method begins as soon as the same $R$ occurs for three consecutive times, as shown in Figure 13 . $R$ obtained from the fault diagnosis algorithm is ' 3 ' and it means the open-switch fault of $S_{a 2}$ occurs in the NPC converter, as presented in Table 2.

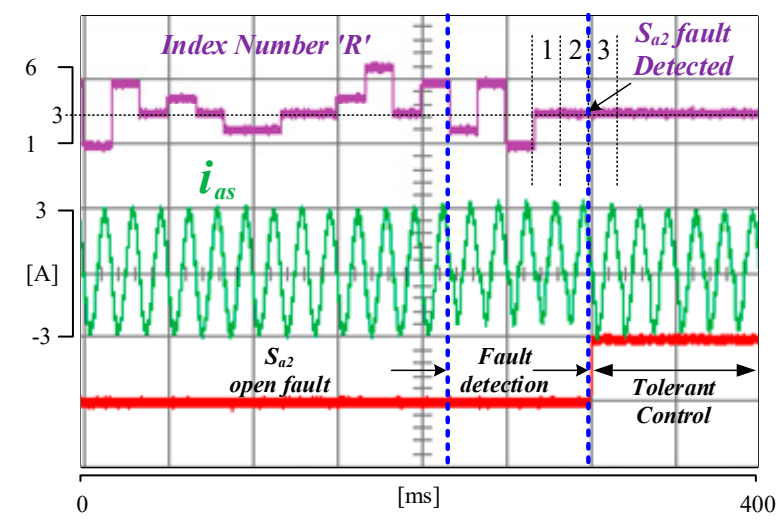

Figure 13. Experimental result for open-switch fault diagnosis algorithm.

Under healthy conditions, as shown in Figure 14a, the DC-link voltage is stably controlled at $400 \mathrm{~V}$ and the three-phase input currents are well balanced with a sinusoidal waveform. After the open-switch fault of $S_{a 2}$ occurs in the three-level NPC rectifier, the three-phase input currents are distorted and unbalanced, as shown in Figure 14b. Notably, the negative current of phase A is seriously distorted because the current flows through the abnormal path of Figure 2f, rather than the path of Figure $2 \mathrm{~d}$. In addition, the DC-link voltage includes the ripple of the grid frequency $(60 \mathrm{~Hz})$ by the distorted input phase currents. In order to improve the system reliability and to avoid additional failures, the fault-tolerant control method must be required for the three-level NPC active rectifier. Figure 14c shows the experimental result of applying the proposed fault-tolerant method to the three-level NPC rectifier. Compared with the waveforms of Figure 14b, the three-phase input current is more balanced and the ripple of the DC-link voltage is also greatly reduced.

Figure 15 shows the DC-link voltage waveforms and X-Y plot for three-phase input currents according to the three operating conditions. In the healthy condition shown in Figure 15a, the current trajectory on the X-Y plot is perfectly circular because the three-phase input currents are well controlled and balanced. So, the DC-link voltage is stably controlled at $400 \mathrm{~V}$. Also, the difference between upper and lower DC-link voltage is almost zero. However, if the open-switch fault of $S_{a 2}$ occurs, the current trajectory on the left half plane of the X-Y plot is distorted, as shown in Figure 15b, because of the unbalanced and distorted three-phase input currents. Furthermore, the imbalance is caused between the upper and lower DC-link voltage. As a result, the DC-link voltage fluctuates with the grid frequency $(60 \mathrm{~Hz})$. If the proposed fault-tolerant control method is applied after the open-switch fault diagnosis, the distorted trajectory of the three-phase current in the X-Y plot is almost restored to the original circular shape, as presented in Figure 15c. Also, the ripple of the DC-link voltage is stabilized and the voltage difference between the upper and lower DC-link capacitors is decreased. These results show that the distorted reference voltage by the fault is compensated by the proposed fault-tolerant method, and that the three-phase input currents are balanced. 


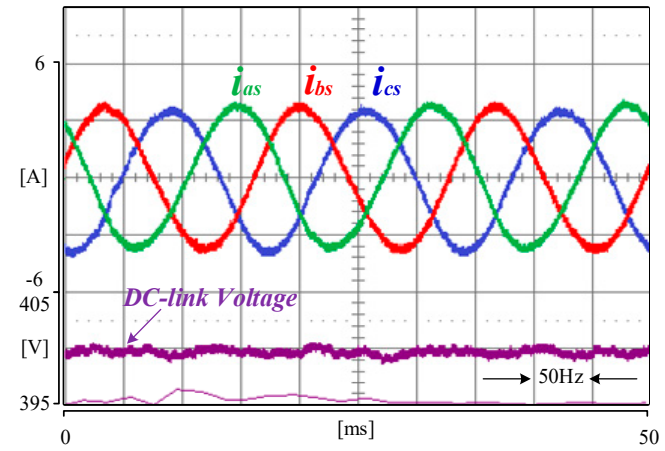

(a)

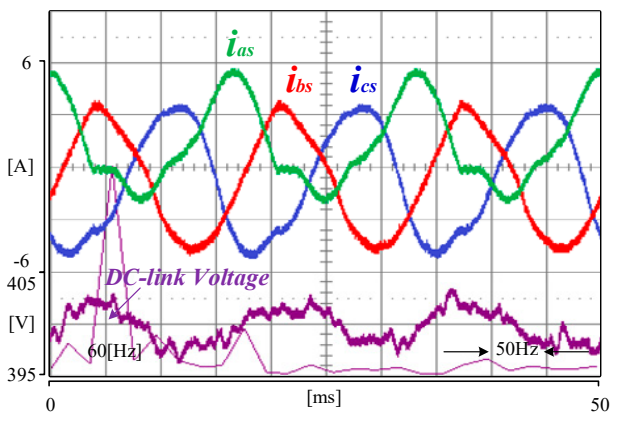

(b)

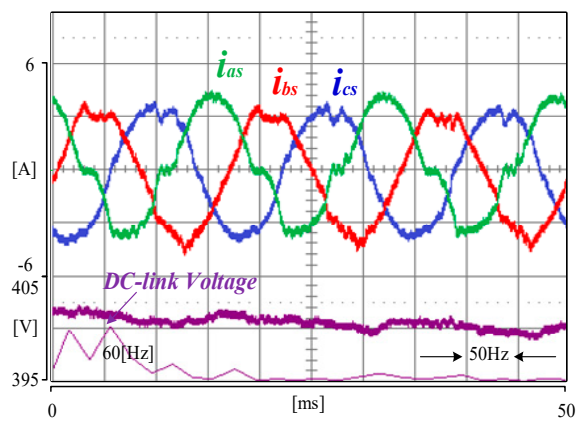

(c)

Figure 14. Three-phase currents, DC-link voltage and FFT results of the DC-link voltage (a) Healthy condition; (b) Open-switch fault $\left(S_{a 2}\right)$ condition; (c) Proposed fault-tolerant control method.

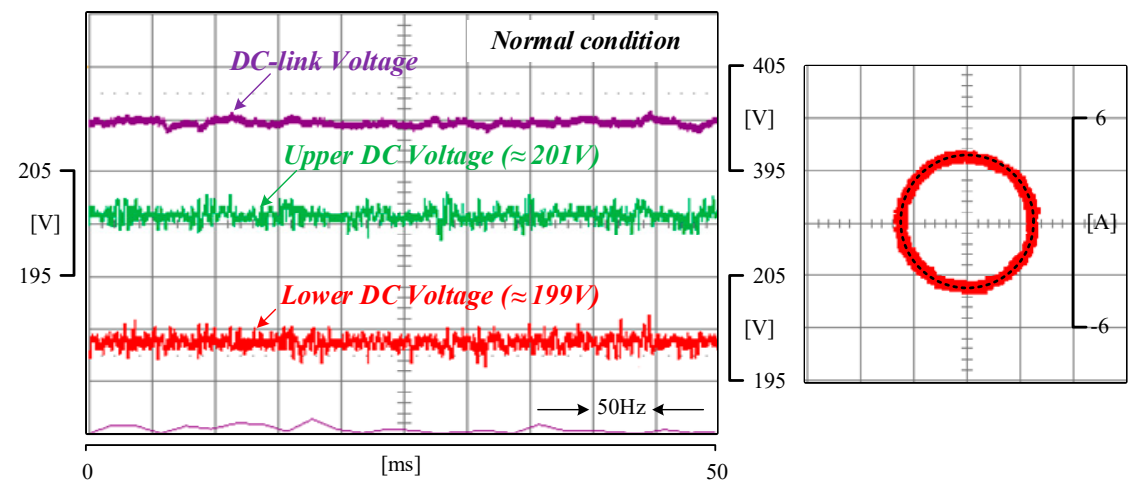

(a)

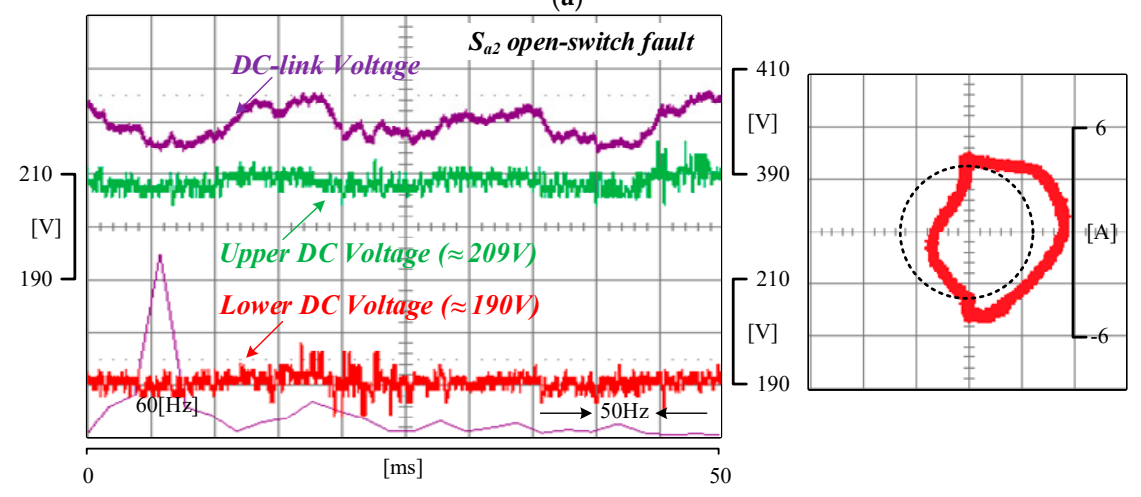

(b)

Figure 15. Cont. 


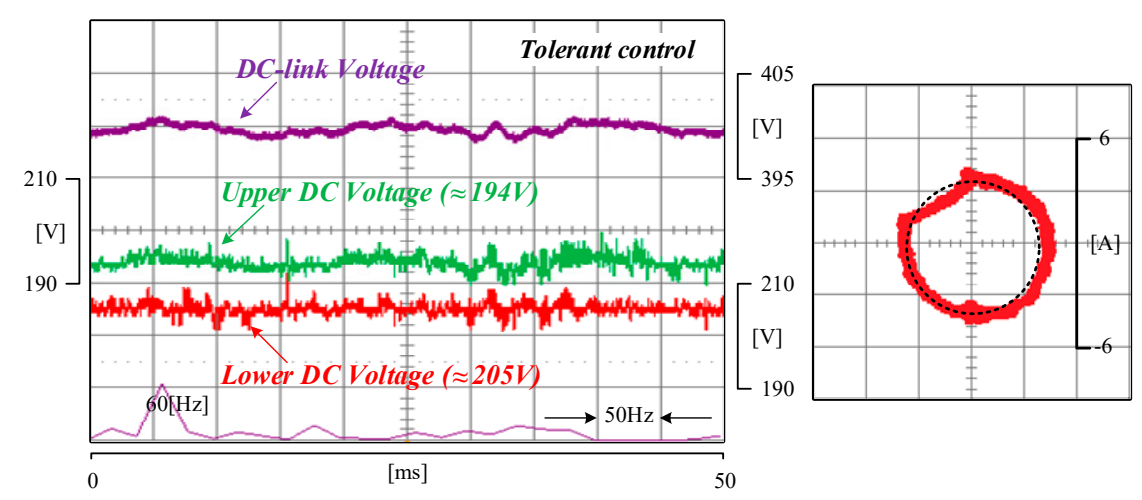

(c)

Figure 15. DC-link voltages and $X-Y$ plot of the three-phase input currents. (a) Healthy condition; (b) open-switch fault $\left(S_{a 2}\right)$ condition; (c) Proposed fault-tolerant control method.

Table 5 describes the numerical results of Figures 14 and 15 for the three different operating conditions. The measured THD and the power factor are obtained by using the power analyzer WT3000. Under healthy conditions, the THD of the three-phase current is about $2.89 \%$, and it satisfies the general standards of the grid interconnection. The ripple of the DC-link capacitor and the voltage difference between the upper and lower DC-link capacitors is $0.5 \mathrm{~V}$, which is small enough so that its effect on the equipment connected to the DC-link is considered negligible. After the open-switch fault occurs, however, the measured THD results are, on average, $17.5 \%$, which is a significantly deteriorated value. Notably, the THD of the faulty phase A is about $24 \%$. Furthermore, the DC-link voltage has a ripple of $10 \mathrm{~V}$; this affects the performance of the equipment connected to the DC-link of the active rectifier. After the fault-tolerant method is applied under the fault condition, the ripple of the DC-link voltage is considerably decreased. So, the effect of the DC-link voltage ripple on the equipment is minimized by the proposed fault-tolerant method. The THD of the three-phase current are slightly improved, but the three-phase input currents are balanced, as shown in Figure 14c.

Table 5. Comparison with numerical result under three conditions.

\begin{tabular}{lcccc}
\hline \multicolumn{2}{c}{ Comparison Factors } & $\begin{array}{c}\text { Healthy } \\
\text { Condition }\end{array}$ & $\begin{array}{c}S_{a 2} \text { Faulty } \\
\text { Condition }\end{array}$ & $\begin{array}{c}\text { Tolerant } \\
\text { Method }\end{array}$ \\
\hline \multirow{2}{*}{ Current Mag. [A] } & Phase A & 3.73 & 3.39 & 3.91 \\
& Phase B & 3.72 & 4.31 & 3.36 \\
& Phase C & 3.73 & 4.24 & 3.67 \\
\hline \multirow{2}{*}{ Current THD [\%] } & Phase A & 2.88 & 24.05 & 18.33 \\
& Phase B & 2.90 & 13.91 & 9.95 \\
& Phase C & 2.88 & 14.62 & 12.23 \\
\hline \multicolumn{2}{c}{ DC-link voltage ripple [V] } & 0.5 & 10 & 2 \\
\hline \multicolumn{2}{c}{ DC-link voltage imbalance [V] } & 0.5 & 20 & 11 \\
\hline \multicolumn{2}{c}{ Power factor } & $\fallingdotseq 1$ & $\fallingdotseq 0.936$ & $\fallingdotseq 0.968$ \\
\hline
\end{tabular}

\section{Conclusions}

This paper proposed a fault diagnosis algorithm and tolerant control method for a single open-switch fault in the three-phase three-level NPC active rectifier. Although the open-switch fault does not cause system shutdown, it degrades both the performance and the reliability of the system because the fault causes distortion of the three-phase input currents and fluctuation of the output DC-link voltage. The proposed fault diagnosis method can find the faulty switch by using the ripple of the DC-link voltage and the phase angle of the grid voltage. The fault-tolerant control method significantly minimizes the effect of the fault by compensating for the distorted reference voltage. 
After the tolerant method is applied, the imbalance and distortion of the three-phase input currents are improved, and the fluctuation of the DC-link voltage is reduced so as not to affect the equipment connected to the DC-link. The effectiveness of the proposed fault diagnosis and tolerant methods are verified through the experimental results.

Author Contributions: J.-H.J. contributed to the research activity and to manuscript writing. H.-K.K. performed experiments and software writing. Y.-D.S. and J.-M.K. provided technical feedback and did supervision of the overall work.

Funding: This research received no external funding.

Acknowledgments: This work was supported by BK21PLUS, Creative Human Resource Development Program for IT Convergence.

Conflicts of Interest: The authors declare no conflict of interest.

\section{References}

1. Choudhury, A.; Pillay, P.; Williamson, S.S. Comparative analysis between two-level and three-level dc/ac electric vehicle traction inverters using a novel dc-link voltage balancing algorithm. IEEE J. Emerg. Sel. Top. Power Electron. 2014, 2, 529-540. [CrossRef]

2. Pou, J.; Zaragoza, J.; Ceballos, S.; Saeedifard, M.; Boroyevich, M. A carrier-based PWM strategy with zero-sequence voltage injection for a three-level neutral-point clamped converter. IEEE Trans. Power Electron. 2012, 27, 642-651. [CrossRef]

3. Ma, K.; Blaabjerg, F. Modulation methods for neutral-point-clamped wind power converter achieving loss and thermal redistribution under low-voltage ride-through. IEEE Trans. Ind. Electron. 2014, 61, 835-845. [CrossRef]

4. Jiang, W.D.; Du, S.W.; Chang, L.C.; Zhang, Y.; Zhao, Q. Hybrid PWM strategy of SVPWM and VSVPWM for NPC three-level voltage-source inverter. IEEE Trans. Power Electron. 2010, 25, 2607-2619. [CrossRef]

5. Lee, J.S.; Lee, K.B. Time-offset injection method for neutral point AC ripple voltage reduction in a three-level inverter. IEEE Trans. Power Electron. 2016, 31, 1931-1941. [CrossRef]

6. Lewicki, A.; Krzeminski, Z.; Abu-Rub, H. Space-vector pulse width modulation for three-level NPC converter with the NP voltage control. IEEE Trans. Ind. Electron. 2011, 58, 5076-5086. [CrossRef]

7. Jiao, Y.; Lee, F.; Lu, S. Space vector modulation for 3-level NPC converter with neutral point voltage balancing and switching loss reduction. IEEE Trans. Power Electron. 2014, 29, 5579-5591. [CrossRef]

8. Jung, J.H.; Park, J.H.; Kim, J.M.; Son, Y.D. DC-Link voltage balance control using fourth-phase for 3-phase 3-level NPC PWM converters with common-mode voltage reduction technique. J. Power Electron. 2019, 19, $108-118$.

9. Song, Y.; Wang, B. Survey on Reliability of Power Electronic Systems. IEEE Trans. Power Electron. 2013, 28, 591-604. [CrossRef]

10. Lu, B.; Sharma, S.K. A literature review of IGBT fault diagnostic and protection methods for power inverter. IEEE Trans. Ind. Appl. 2009, 45, 1770-1777.

11. Huang, F.; Flett, F. IGBT fault protection based on di/dt feedback control. In Proceedings of the IEEE Power Electronics Specialists Conference, Orlando, FL, USA, 17-21 June 2007; pp. 1478-1484.

12. Li, X.; Xu, D.; Zhu, H.; Cheng, X.; Yu, Y.; Ng, W.T. Indirect IGBT over-current detection technique via gate voltage monitoring and analysis. IEEE Trans. Power Electron. 2019, 34, 3615-3622. [CrossRef]

13. Im, W.S.; Kim, J.M.; Lee, D.C.; Lee, K.B. Diagnosis and fault-tolerant control of three-phase AC-DC PWM converter system. IEEE Trans. Ind. Appl. 2013, 49, 1539-1547. [CrossRef]

14. Freire, N.M.A.; Estima, J.O.; Marques Cardoso, A.J. Open-circuit fault diagnosis in PMSG drives for wind turbine applications. IEEE Trans. Ind. Electron. 2013, 60, 3957-3967. [CrossRef]

15. Ko, Y.J.; Lee, K.B.; Lee, D.C.; Kim, J.M. Fault diagnosis of three-parallel voltage-source converter for a high-power wind turbine. IET Power Electron. 2012, 5, 1058-1067. [CrossRef]

16. Zhao, H.; Cheng, L. Open-circuit fault diagnosis in back-to-back converters of DF wind turbine. IET Renew. Power Gener. 2017, 11, 417-424. [CrossRef]

17. Choi, U.M.; Jeong, H.G.; Lee, K.B.; Blaabjerg, F. Method for detecting an open-switch fault in a grid-connected NPC inverter system. IEEE Trans. Power Electron. 2012, 27, 2726-2739. [CrossRef] 
18. Lee, J.S.; Lee, K.B.; Blaabjerg, F. Open-switch fault diagnosis method of a back-to-back converter using NPC topology for wind turbine systems. IEEE Trans. Ind. Appl. 2015, 51, 325-335. [CrossRef]

19. Lee, H.H.; Dzung, P.Q.; Hoa, T.P.; Phuong, L.M.; Bac, N.X. Fault diagnosis using ANN for Three-level NPC Inverter fed induction motor drive. In Proceedings of the IEEE Region Conference, Fukuoka, Japan, 21-24 November 2010; pp. 2148-2153.

20. Baghli, M.; Delpha, C.; Diallo, D.; Hallouche, A. Three-level inverter fault diagnosis and diagnosis using current-based statistical analysis. Proceeding of the Prognostics and System Health Management Conference, Chongqing, China, 26-28 October 2018; pp. 686-691.

21. Li, H.; Guo, Y.; Xia, J.; Li, Z.; Zhang, X. Open-circuit fault diagnosis for a fault-tolerant three-level neutral-point-clamped STATCOM. IET Power Electron. 2019, 12, 810-816. [CrossRef]

22. Lee, J.S.; Lee, K.B. An open-switch fault diagnosis method and tolerance controls based on SVM in a grid-connected T-type rectifier with unity power factor. IEEE Trans. Ind. Electron. 2014, 61, 7092-7104. [CrossRef]

23. Kim, T.J.; Lee, W.C.; Hyun, D.S. Diagnosis method for open circuit fault in neutral-point clamped inverter systems. IEEE Trans. Ind. Electron. 2009, 56, 2754-2763.

24. Fazio, P.; Maragliano, G.; Marchesoni, M.; Parodi, G. A new fault diagnosis method for NPC converter. In Proceedings of the 14th Europe Conference Power Electronics, Birmingham, UK, 30 August-1 September 2011; pp. 1-10.

25. Ku, H.K.; Im, W.S.; Kim, J.M.; Suh, Y.S. Fault diagnosis and tolerant control of 3-phase NPC active rectifier. In Proceedings of the Energy Conversion Congress and Exposition, Raleigh, NC, USA, 15-20 September 2012; pp. 4519-4524.

26. Ku, H.K.; Kim, J.M. Multiple open-switch faults diagnosis and faults tolerant method for three-level three-phase NPC active rectifier. In Proceedings of the IEEE Industrial Electronics Society Conference, Vienna, Austria, 10-13 November 2013; pp. 1062-1067.

27. Lee, J.S.; Lee, K.B. Open-circuit fault-tolerance control for a three-level NPC/T-type rectifier in wind turbine systems. IEEE Trans. Ind. Electron. 2015, 62, 1012-1021. [CrossRef]

28. Lee, J.S.; Lee, K.B. Open-circuit fault tolerant control for outer switches of three-level rectifier in wind turbine systems. IEEE Trans. Power Electron. 2016, 31, 3806-3815. [CrossRef]

29. Wu, B. High-Power Converters and AC Drives; Wiley: Hoboken, NJ, USA, 2006.

(C) 2019 by the authors. Licensee MDPI, Basel, Switzerland. This article is an open access article distributed under the terms and conditions of the Creative Commons Attribution (CC BY) license (http://creativecommons.org/licenses/by/4.0/). 